\title{
Isolation and characterisation of intestinal spirochaetes
}

\author{
DS TOMPKINS, SALLY J FOULKES,* PGR GODWIN, AP WEST \\ From the Department of Microbiology, University of Leeds, Leeds, and the *Bacteriology Laboratory, Bradford \\ Royal Infirmary, Bradford
}

SUMMARY Faeces or rectal swabs from 1527 subjects were examined for the presence of intestinal spirochaetes by anaerobic culture on blood agar incorporating spectinomycin $(400 \mathrm{mg} / \mathrm{l})$. Twenty three specimens $(1.5 \%)$ were positive, and only one of these came from a patient with diarrhoea. All positive specimens came from either Asians or known homosexuals. Comparative tests showed a close phenotypic similarity between the human isolates and non-pathogenic porcine intestinal spirochaetes. These organisms differ from Brachyspira aalborgi, a spirochaete isolated from subjects with histologically confirmed intestinal spirochaetosis.

Organisms similar to spirochaetes were first observed in faeces, using the light microscope, towards the end of the last century. ${ }^{1}$ Associations were noted with cholera, dysentery, and other intestinal conditions, but later studies described the presence of spirochaetes in the faeces of normal healthy subjects, and similar organisms were found in the intestinal tracts of various animal species. ${ }^{2}$ A wide variation was noted in the incidence of spiral organisms in specimens collected in different geographical areas. $^{2-4}$

Further interest was stimulated by the advent of electron microscopy. True spirochaetes with axial fibrils were shown in the intestinal tracts of man and animals. ${ }^{5-7}$ Some reports suggested that overgrowth of these organisms, "intestinal spirochaetosis," was associated with various intestinal disorders, including diarrhoea and rectal bleeding. ${ }^{4-10}$ In pigs some spirochaetes are present as part of the normal flora, but Treponema hyodysenteriae gives rise to swine dysentery, and other similar organisms cause diarrhoea. ${ }^{61112} \mathrm{~A}$ method developed for the culture of porcine intestinal spirochaetes ${ }^{13}$ has been used to isolate similar organisms from homosexuals, ${ }^{14}$ a group known to have a high incidence of intestinal spirochaetosis. ${ }^{15}$ The purpose of this study was to determine the incidence of these organisms in other groups of the local population by culturing faecal specimens or rectal swabs and to determine any association between carriage and intestinal disorders.

\section{Material and methods}

\section{ISOLATION OF STRAINS}

Two kinds of specimen were examined for the presence of spirochaetes: faeces submitted to the bacteriology laboratory, Bradford Royal Infirmary, and the diagnostic laboratory, Department of Microbiology, University of Leeds, for the diagnosis of diarrhoea or screening for enteric pathogens; and rectal swabs, taken from homosexuals and surgical outpatients, and some faeces from homosexuals, taken specifically for spirochaete culture. Multiple samples were received from some homosexuals, but only one specimen was examined from each of the other patients.

Faeces were transported to the laboratory at ambient temperature and cultured within 48 hours of production. Swabs were transported in Stuart's medium (Transwab), cultured within 24 hours of sampling, and if stored overnight, maintained at $4^{\circ} \mathrm{C}$.

All specimens collected in Bradford were taken over three months from December 1983 to March 1984 (Table 1). Specimens examined in Leeds were collected intermittently over three years (1981-84); few of these came from Asian patients (Table 2).

Specimens were inoculated on to a selective medium comprising blood agar base No 2 (Oxoid), $5 \%$ defibrinated horse blood, and spectinomycin (400 $\mathrm{mg} / \mathrm{l})$. Plates were incubated at $37^{\circ} \mathrm{C}$ for at least five days anaerobically $(90 \%$ hydrogen, $10 \%$ carbon dioxide). Loosely coiled Gram negative spirochaetes produced a typical film like growth with weak $\beta$ haemolysis. ${ }^{14}$ 
Table 1 Sources of specimens examined for presence of intestinal spirochaetes (Bradford area) (Figures in parentheses are numbers (\%))

\begin{tabular}{lcc}
\hline Source & Total No of patients & Patients colonised by spirochaetes \\
\hline Environmental health screening of contacts and carriers of & 338 & $4(12)$ \\
$\quad$ gastrointestinal pathogens & 43 & $8(18 \cdot 6)$ \\
Immigration screening clinics & 74 & $3(4 \cdot 1)$ \\
Antenatal screening & 10 & 0 \\
Screening before domestic employment & 201 & 0 \\
Infectious diseases hospital patients & 150 & 0 \\
General hospital patients & 179 & $1(0 \cdot 6)$ \\
General practice patients & & \\
\hline
\end{tabular}

Three porcine strains were donated by D Hunter, Ministry of Agriculture, Fisheries, and Food, Leeds: P18A, a known pathogenic strain of $T r$ hyodysenteriae ${ }^{16}$ producing complete haemolysis on blood agar; and two non-pathogens, PWS and PWS/A, producing weaker haemolysis. These were used in comparative tests with three isolates from homosexuals (A, B, and C) and 16 isolates from Asians. Some isolates came from members of the same household; $1,2,3 ; 4,5$; and 15,16 are the related organisms.

Growth was attempted on blood agar at $30^{\circ} \mathrm{C}$, $37^{\circ} \mathrm{C}$, and $43^{\circ} \mathrm{C}$ incubated anaerobically, and at $37^{\circ} \mathrm{C}$ incubated aerobically and microaerophilically.

\section{CARBOHYDRATE FERMENTATION}

Carbohydrate fermentation was tested on solid media by the method of Phillips ${ }^{17}$ and included the recommended controls. Carbohydrates were incorporated into blood agar (without spectinomycin) to a final concentration of $1 \%(w / v)$. The agar was divided into sections with ditches and heavily inoculated with spirochaetes. After 72 hours of anaerobic incubation plugs of agar were withdrawn using plastic drinking straws and placed in the wells of microtitre plates. Four drops of $0.04 \%(w / v)$ bromothymol blue indicator solution were added to each well with a pasteur pipette. Colour changes in the indicator were compared with controls of plugs of agar taken from inoculated plates containing no carbohydrate and uninoculated plates containing the various carbohydrates.

\section{AESCULIN HYDROLYSIS}

Aesculin hydrolysis was tested by the method of Phillips ${ }^{17}$ using blood agar as the basal medium.

\section{INDOLE PRODUCTION}

This was tested by two methods. A sterile paper disc was placed on an area of growth on a blood agar plate and left for 10 minutes, then transferred to a well of a microtitre plate. Four drops of xylene and four drops of Kovac's reagent were then added: a pink colouration denoted formation of indole.

Indole formation in broth was tested on cultures grown in tryptic soy broth (Difco) with $10 \%$ unheated fetal calf serum. ${ }^{18}$ The broths were incubated in an anaerobic atmosphere for five days and tested for indole production by the addition of a few drops of xylene and Kovac's reagent.

\section{ENZYMATIC REACTIONS}

Enzymatic reactions were examined using the API ZYM system (API System SA) as described by Hunter and Wood. ${ }^{19}$ Colours of the cupules in the test strips were compared with those of a chart supplied with the kit and graded from 0 to 5 according to intensity.

\section{FATTY ACID METHYL ESTERS}

Fatty acid methyl esters were produced using a technique based on that of Moss. ${ }^{20}$ The organisms were grown on tryptic soy agar (Difco) with added $0.5 \%$ glucose, $3 \%$ fetal calf serum, $0.2 \% \mathrm{NaHCO}_{3}$ and $0.05 \%$ cysteine hydrochloride. ${ }^{21}$ After incubation for 72 hours the cells were scraped from the plate, washed in sterile saline, and after centrifugation at $13000 \mathrm{rpm}$ (Microcentaur MSE) were resuspended in $1 \mathrm{ml}$ of $5 \%$ $\mathrm{NaOH}$ in $50 \%$ methanol. The sample was heated for 30 minutes at $100^{\circ} \mathrm{C}$ in a heating block. The tube was cooled and the $\mathrm{pH}$ adjusted to $<2$ using $6 \mathrm{M}$ hydrochloric acid: $1 \mathrm{ml}$ of $14 \% \mathrm{BF}_{3} /$ methanol (BDH) was

Table 2 Sources of specimens examined for presence of intestinal spirochaetes (Leeds area)

\begin{tabular}{|c|c|c|}
\hline Source & Total No of patients & Patients colonised by spirochaetes \\
\hline $\begin{array}{l}\text { Faeces submitted to diagnostic laboratory for culture } \\
\text { Faeces of food handlers submitted for screening purposes } \\
\text { Rectal swabs of patients in general surgical outpatients clinic } \\
\text { Rectal swabs and faeces from homosexuals attending department } \\
\text { of genito-urinary medicine }\end{array}$ & $\begin{array}{r}384 \\
44 \\
70 \\
34\end{array}$ & $\begin{array}{l}0 \\
0 \\
0 \\
7(20 \cdot 6 \%)\end{array}$ \\
\hline
\end{tabular}


Table 3 Results of culture of specimens received from seven homosexuals colonised by spirochaetes

\begin{tabular}{llll}
\hline Patient & Time interval between specimens & Type of specimen & Presence of spirochaetes \\
\hline A & & Rectal swab & + \\
B (1) & & Faeces & + \\
C (2) & Faeces & + \\
D (1) & Rectal swab & + \\
(2) & Faeces & - \\
(3) & 4 months & Rectal swab & - \\
(1) & 8 months & Faeces & + \\
G & 2 weeks & Rectal swab & + \\
\hline
\end{tabular}

added and the sample heated for five minutes at $80-85^{\circ} \mathrm{C}$. After cooling 1-2 drops of saturated sodium chloride solution was added and the esters were extracted twice with $1 \mathrm{ml}$ of chloroform:hexane (1:4). The combined extracts were dried down under nitrogen and the extract made up to $0.1 \mathrm{ml}$ with chloroform. The samples were analysed immediately or stored desiccated at $-20^{\circ} \mathrm{C}$.

Analysis was carried out using a 10 foot $\times \frac{1}{8}$ inch glass column packed with $3 \%$ OV-101 on Chromosorb WHP 100/120 mesh and a 6 foot $\times \frac{1}{8}$ inch glass column packed with $10 \%$ SP-2300 on Supelcoport. (Columns supplied by Chrompack, London). These were installed in a Perkin-Elmer Sigma 3b with Sigma 15 data station equipped with a flame ionisation detector. For both columns the injector and detector temperature was maintained at $280^{\circ} \mathrm{C}$, and a temperature programme was used with an initial temperature of $150^{\circ} \mathrm{C}$ rising to $240^{\circ} \mathrm{C}\left(230^{\circ} \mathrm{C}\right.$ for $\left.\mathrm{SP}-2300\right)$ at $4^{\circ} \mathrm{C} /$ minute.

The peaks were identified using methyl ester standards (Supelco, Sigma) and by comparison with organisms of known fatty acid composition (Legionella pneumophila, Pseudomonas aeruginosa, and Pseudomonas cepacia).

\section{ANTIBIOTIC SENSITIVITIES}

A dry swab was used to pick up a heavy inoculum of spirochaetes from a plate and this was spread over the surface of a blood agar plate to form a dense lawn. Antibiotic discs (Mast laboratories) were placed on the agar and the plates incubated anaerobically for $\mathbf{4 8}$ hours.

Growth or haemolysis to the edge of the disc was read as resistant; any clear zone around the disc was read as sensitive.

Antibiotics tested were; penicillin 1 unit, cephradine $30 \mu \mathrm{g}$, tetracycline $10 \mu \mathrm{g}$, chloramphenicol $25 \mu \mathrm{g}$, metronidazole $2.5 \mu \mathrm{g}$, fusidic acid $10 \mu \mathrm{g}$, vancomycin $25 \mu \mathrm{g}$, and colistin sulphate $25 \mu \mathrm{g}$. Chromogenic cephalosporin solution (Nitrocefin 87/312, Glaxo United Kingdom) was used to test for $\beta$ lac- tamase production. ${ }^{22}$

\section{Results}

\section{CULTURE TECHNIQUES}

Spirochaetes were recovered on the selective medium from swabs dipped in a suspension of $10^{3}$ organisms $/ \mathrm{ml}$ of pooled liquid faeces and stored in transport medium at $4^{\circ} \mathrm{C}$ for 48 hours and from swabs dipped in a suspension of $10^{5}$ organisms $/ \mathrm{ml}$ of pooled liquid faeces and stored in transport medium either at room temperature or $4^{\circ} \mathrm{C}$ for seven days. Viable counts of suspensions of $10^{3}$ or $10^{5}$ organisms $/ \mathrm{ml}$ of liquid faeces were of the same order (within one $\log _{10}$ ) before and after storage at room temperature, or $4^{\circ} \mathrm{C}$, for 48 hours when plated on the selective medium. Viable counts of pure suspensions of spirochaetes were within one $\log _{10}$ on blood agar with and without spectinomycin $(400 \mathrm{mg} / \mathrm{l})$. All experiments were duplicated with different isolates.

Spectinomycin at a concentration of $400 \mathrm{mg} / \mathrm{l}$ has been shown not to change viable counts of $T r$ hyodysenteriae but to inhibit the intestinal flora of pig faeces by $99.9 \%{ }^{23} \operatorname{Tr}$ hyodysenteriae survives in specimens of dysenteric pig faeces in the post for at least four days and up to $\mathbf{4 8}$ days at temperatures between $0^{\circ} \mathrm{C}$ and $10^{\circ} \mathrm{C} .^{24}$

\section{ISOLATION OF SPIROCHAETES}

Table 1 gives a full analysis of specimens of faeces collected in Bradford between December 1983 and March 1984. These specimens came from 995 patients of whom 550 were aged under 16 years, and $16(1.6 \%)$ had spirochaetes present on culture. Three hundred and thirty of the patients were Asians and all 16 positive results were from this group $(4 \cdot 8 \%)$. The patients with spirochaetes were aged 2-37 years (nine aged under 16 years), and 12 had visited or had been living in the Indian subcontinent during the preceding year. Only one 2 year old patient had symptoms at the time of sampling, and no other enteric pathogens were found in this case. Known enteric pathogens were 
Table 4 Comparison of human and porcine intestinal spirochaetes

\begin{tabular}{|c|c|c|c|c|c|c|c|c|c|}
\hline Strain & P18A & PWSA & PWS & $A$ & $B$ & $C$ & 1 & 2 & 3 \\
\hline $\begin{array}{l}\text { Alkaline phosphatase } \\
\text { Esterase C4 } \\
\text { Esterase lipase C8 } \\
\text { Acid phosphatase } \\
\alpha \text { Galactosidase } \\
\beta \text { Galactosidase } \\
\alpha \text { Glucosidase } \\
\beta \text { Glucosidase } \\
\text { Aesculin hydrolysis } \\
\text { Indole (Disc) } \\
\text { Indole broth } \\
\text { Glucose } \\
\text { Fructose } \\
\text { Maltose } \\
\text { Sucrose } \\
\text { Lactose } \\
\text { Trehalose } \\
\text { Mannitol } \\
\text { Xylose } \\
\text { Mannose } \\
\text { Arabinose } \\
\text { Cellobiose } \\
\text { Galactose }\end{array}$ & $\begin{array}{l}3 \\
3 \\
3 \\
2 \\
0 \\
5 \\
3 \\
3 \\
+ \\
+ \\
+1- \\
+ \\
+ \\
+ \\
+ \\
+ \\
+ \\
+ \\
+1- \\
+ \\
+1- \\
+ \\
+\end{array}$ & $\begin{array}{l}2 \\
4 \\
2 \\
0 \\
0 \\
5 \\
3 \\
3 \\
+ \\
+ \\
+1- \\
+ \\
+ \\
+ \\
+ \\
+ \\
+ \\
+1- \\
+ \\
+ \\
+1- \\
+ \\
W\end{array}$ & $\begin{array}{l}1 \\
4 \\
1 \\
2 \\
5 \\
0 \\
0 \\
+ \\
+ \\
\text { NT } \\
+ \\
+ \\
+ \\
+ \\
+ \\
+ \\
+ \\
+ \\
+ \\
+ \\
+ \\
\mathbf{W}\end{array}$ & $\begin{array}{l}2 \\
5 \\
4 \\
1 \\
0 \\
5 \\
0 \\
0 \\
+ \\
+ \\
\overline{+} \\
+ \\
+ \\
+ \\
+ \\
+ \\
+ \\
- \\
+ \\
+ \\
+ \\
\mathbf{w}\end{array}$ & $\begin{array}{l}2 \\
5 \\
4 \\
1 \\
1 \\
5 \\
0 \\
0 \\
+ \\
+ \\
+ \\
+ \\
+ \\
+ \\
+ \\
+ \\
+ \\
+ \\
+ \\
+ \\
+ \\
+ \\
+\end{array}$ & $\begin{array}{l}1 \\
5 \\
4 \\
1 \\
2 \\
5 \\
3 \\
0 \\
+ \\
+ \\
+ \\
+ \\
+ \\
+ \\
+ \\
+ \\
+ \\
+ \\
+ \\
+ \\
+ \\
+ \\
+\end{array}$ & $\begin{array}{l}1 \\
4 \\
4 \\
1 \\
5 \\
5 \\
2 \\
0 \\
+ \\
+ \\
+ \\
+ \\
+ \\
+ \\
+ \\
+ \\
+ \\
w /- \\
+ \\
+ \\
+ \\
+ \\
w\end{array}$ & $\begin{array}{l}1 \\
5 \\
4 \\
1 \\
5 \\
5 \\
2 \\
0 \\
+ \\
+ \\
+1- \\
+ \\
+ \\
+ \\
+ \\
+ \\
+ \\
+ \\
+ \\
+ \\
+ \\
+ \\
+\end{array}$ & $\begin{array}{l}1 \\
2 \\
2 \\
1 \\
0 \\
4 \\
0 \\
0 \\
+ \\
+ \\
+ \\
+ \\
+ \\
+ \\
+ \\
+ \\
+ \\
+ \\
+ \\
+ \\
+ \\
+ \\
+\end{array}$ \\
\hline
\end{tabular}

found in seven of the remaining 11 patients: Shigella flexneri (2), Ascaris (2), Hymenolepis nana (1), Trichuris and hookworm (1), Entamoeba histolytica (1).

Further specimens were examined in Leeds (Table 2). Sixty nine specimens, 32 faeces, and 37 rectal swabs, were received from 34 homosexuals. Three faeces and five swabs were positive on culture for spirochaetes, two of the swabs coming from the same patient (Table 3).

\section{COMPARATIVE STUDIES}

All strains grew under anaerobic conditions on $5 \%$ horse blood agar at $37^{\circ} \mathrm{C}$ and $43^{\circ} \mathrm{C}$ but not $30^{\circ} \mathrm{C}$. There was no growth aerobically or microaerophilically. Cellular and colonial morphology has been described previously. ${ }^{14} 18$

The pathogenic porcine isolate showed complete $\beta$ haemolysis, the two non-pathogenic strains and all human strains were weakly $\beta$ haemolytic when incu- bated as described on blood agar. All strains were cytochrome oxidase and catalase negative. Carbohydrate fermentation, indole production, and aesculin hydrolysis were all tested on at least two occasions. Table 4 gives the results. It has been noted previously ${ }^{1116}$ that biochemical tests on these organisms are not always reproducible, and inconsistent results are noted in the Table. All strains fermented glucose, fructose, maltose, sucrose, lactose, mannose, cellobiose, and galactose. Fermentation of mannitol, xylose, trehalose, and arabinose was variable.

Enzymatic reactions were tested at least twice, and all readings were reproducible within 1 mark of activity. The readings quoted were all taken on one occasion as minor differences in colour were more easily detected by direct comparison. All strains produced alkaline phosphatase and large amounts of esterase $\left(C_{4}\right)$, esterase lipase $\left(C_{8}\right)$, and $\beta$ galactosidase. Prod-

Table 5 Fatty acids detected in spirochaetes ( $\%$ of total area of esters for each organism)

\begin{tabular}{|c|c|c|c|c|c|c|c|c|c|c|c|c|}
\hline $\begin{array}{l}\text { Fatty acid with } \\
\text { retention time } \\
\text { (minutes) for } O V \\
101 \text { column }\end{array}$ & $\begin{array}{l}* 13: 1 \\
(7 \cdot 3)\end{array}$ & $\begin{array}{l}30 H- \\
14: 0 \\
(8.6)\end{array}$ & $\begin{array}{l}14: 0 \\
(9.6)\end{array}$ & $\begin{array}{l}i 15: 0 \\
(10.9)\end{array}$ & $\begin{array}{l}15: 0 \\
(11 \cdot 5)\end{array}$ & $\begin{array}{l}16: 0 \\
(14 \cdot 0)\end{array}$ & $\begin{array}{l}I U \\
(15 \cdot 6)\end{array}$ & $\begin{array}{l}a 17: 0 \\
(15 \cdot 7)\end{array}$ & $\begin{array}{l}17: 0 \\
(16 \cdot 4)\end{array}$ & $\begin{array}{l}18: 1 \\
(18.0)\end{array}$ & $\begin{array}{l}18: 0 \\
(18 \cdot 7)\end{array}$ & $\begin{array}{l}22: 0 \\
(23 \cdot 2)\end{array}$ \\
\hline $\begin{array}{l}\text { PWS } \\
\text { PWSA } \\
\text { A } \\
\text { C } \\
2 \\
7 \\
11\end{array}$ & $\begin{array}{l}14 \cdot 2 \\
21 \cdot 0 \\
13 \cdot 2 \\
15 \cdot 0 \\
10.6 \\
16 \cdot 8 \\
14 \cdot 3\end{array}$ & $\begin{array}{l}12 \cdot 2 \\
14 \cdot 0 \\
13 \cdot 2 \\
12 \cdot 5 \\
16 \cdot 7 \\
19 \cdot 6 \\
17 \cdot 9\end{array}$ & $\begin{array}{r}11 \cdot 1 \\
11 \cdot 0 \\
9.4 \\
8.8 \\
8.5 \\
7.6 \\
8.7\end{array}$ & $\begin{array}{l}24 \cdot 0 \\
26 \cdot 0 \\
30 \cdot 8 \\
20 \cdot 0 \\
21 \cdot 7 \\
17 \cdot 0 \\
28 \cdot 5\end{array}$ & $\begin{array}{l}5 \cdot 4 \\
3 \cdot 0 \\
\text { Tr } \\
1 \cdot 4 \\
4 \cdot 4 \\
3 \cdot 1\end{array}$ & $\begin{array}{l}28 \cdot 8 \\
22 \cdot 0 \\
31 \cdot 0 \\
36 \cdot 0 \\
35 \cdot 7 \\
27 \cdot 8 \\
27 \cdot 0\end{array}$ & $\begin{array}{l}- \\
- \\
- \\
\frac{5}{5}\end{array}$ & $\begin{array}{l}\text { Tr } \\
1 \cdot 2 \\
2 \cdot 7 \\
3 \cdot 0 \\
-\end{array}$ & $\begin{array}{l}\text { Tr } \\
- \\
1 \cdot 0 \\
\text { Tr } \\
1 \cdot 3 \\
-\end{array}$ & $\begin{array}{l}\text { Tr } \\
\overline{1 \cdot 7} \\
- \\
-\end{array}$ & $\begin{array}{l}\text { Tr } \\
1 \cdot 7 \\
\operatorname{Tr} \\
2 \cdot 0 \\
\operatorname{Tr} \\
1 \cdot 3 \\
-\end{array}$ & $\begin{array}{l}- \\
\frac{-}{10} \\
- \\
-\end{array}$ \\
\hline
\end{tabular}

* = presumed identity.

Tr $=$ trace, $<1 \%$.

IU = Identity unknown. 


\begin{tabular}{|c|c|c|c|c|c|c|c|c|c|c|c|c|}
\hline 4 & & 6 & 7 & 8 & 9 & 10 & 11 & 12 & 13 & 14 & $\underbrace{15}$ & 16 \\
\hline $\begin{array}{l}1 \\
4 \\
3 \\
1 \\
0 \\
4 \\
0 \\
0 \\
+ \\
- \\
- \\
+ \\
+ \\
+ \\
+ \\
+ \\
+ \\
w \\
+ \\
+ \\
+ \\
+ \\
+ \\
\end{array}$ & $\begin{array}{l}2 \\
5 \\
4 \\
1 \\
5 \\
5 \\
2 \\
0 \\
+ \\
- \\
+ \\
+ \\
+ \\
+ \\
+ \\
+ \\
+ \\
+ \\
+ \\
+ \\
+ \\
+ \\
w\end{array}$ & $\begin{array}{l}1 \\
4 \\
3 \\
1 \\
0 \\
4 \\
0 \\
0 \\
+ \\
+ \\
+1- \\
+ \\
+ \\
+ \\
+ \\
+ \\
+1- \\
+ \\
+1- \\
+ \\
+ \\
+ \\
+\end{array}$ & $\begin{array}{l}2 \\
3 \\
3 \\
1 \\
5 \\
5 \\
2 \\
0 \\
+ \\
+ \\
+ \\
+ \\
+ \\
+ \\
+ \\
+ \\
+ \\
+ \\
+ \\
+ \\
+ \\
+ \\
+\end{array}$ & $\begin{array}{l}1 \\
5 \\
4 \\
1 \\
2 \\
5 \\
0 \\
0 \\
+ \\
+ \\
\mathbf{N T} \\
\mathbf{w} \\
\mathbf{w} \\
+ \\
+ \\
\mathbf{w} \\
\mathbf{w} \\
\bar{w} \\
\mathbf{w} /- \\
+ \\
\mathbf{w} \\
+ \\
\mathbf{w}\end{array}$ & $\begin{array}{l}2 \\
4 \\
4 \\
1 \\
1 \\
5 \\
0 \\
0 \\
+ \\
+ \\
+ \\
+ \\
+ \\
+ \\
+ \\
+ \\
+ \\
+ \\
+ \\
+ \\
+ \\
+ \\
w\end{array}$ & $\begin{array}{l}1 \\
4 \\
3 \\
1 \\
1 \\
5 \\
0 \\
0 \\
+ \\
- \\
- \\
+ \\
+ \\
+ \\
+ \\
+ \\
w \\
w /- \\
+ \\
+ \\
+ \\
+ \\
+\end{array}$ & $\begin{array}{l}1 \\
4 \\
4 \\
1 \\
4 \\
4 \\
2 \\
0 \\
+ \\
+ \\
+1- \\
+ \\
+ \\
+ \\
+ \\
+ \\
+ \\
+ \\
+1- \\
+ \\
+ \\
+ \\
+\end{array}$ & $\begin{array}{l}1 \\
4 \\
3 \\
2 \\
0 \\
4 \\
0 \\
0 \\
+ \\
- \\
- \\
+ \\
+ \\
+ \\
+ \\
+ \\
+ \\
+ \\
+ \\
+ \\
+ \\
+\end{array}$ & $\begin{array}{l}1 \\
4 \\
3 \\
1 \\
0 \\
4 \\
0 \\
0 \\
+ \\
- \\
+ \\
+ \\
+ \\
+ \\
+ \\
+ \\
+1- \\
- \\
w \\
+ \\
+ \\
+ \\
+\end{array}$ & $\begin{array}{l}2 \\
4 \\
2 \\
1 \\
0 \\
5 \\
0 \\
0 \\
+ \\
- \\
+ \\
+ \\
+ \\
+ \\
+ \\
+ \\
+ \\
+ \\
+ \\
+ \\
+ \\
+\end{array}$ & $\begin{array}{l}2 \\
4 \\
2 \\
0 \\
0 \\
5 \\
0 \\
0 \\
+ \\
- \\
N T \\
+ \\
+ \\
+ \\
+ \\
+ \\
+ \\
w /- \\
+ \\
+ \\
+ \\
+ \\
+\end{array}$ & $\begin{array}{l}1 \\
4 \\
3 \\
0 \\
0 \\
5 \\
0 \\
0 \\
+ \\
+ \\
+ \\
+ \\
+ \\
+ \\
+ \\
+ \\
- \\
+ \\
+ \\
+ \\
+ \\
+ \\
+\end{array}$ \\
\hline
\end{tabular}

separate occasions; \} indicates strains from subjects of the same household.

uction of acid phosphatase, $\alpha$ galactosidase, and $\alpha$ glucosidase was variable. Table 5 shows the results of cellular fatty acid analysis, expressed as a percentage of the total area of the esters detected. Spirochaetes isolated from members of the same household did not give identical reactions in the comparative tests used (Table 4).

All strains were sensitive to metronidazole, tetracycline, fusidic acid, and chloramphenicol and resistant to vancomycin and colistin sulphate. Sensitivity to the $\beta$ lactam agents varied, depending on length of incubation and inoculum. Four of the human strains gave no zone of inhibition to penicillin and a weakly positive reaction with the chromogenic cephalosporin test for $\beta$ lactamase production.

\section{Discussion}

In 1981 we reported the isolation of intestinal spirochaetes from homosexuals using blood agar containing spectinomycin incubated anaerobically. ${ }^{14}$ Subsequently, similar organisms were isolated from faeces in Italy, ${ }^{1825}$ Belgium and Rwanda, ${ }^{26}$ and from the blood and faeces of one French patient. ${ }^{27}$

These organisms resemble pathogenic and nonpathogenic spirochaetes isolated from pigs and other animals, both morphologically and in cultural characteristics. Electron microscopy has shown five axial fibrils in most of the human isolates ${ }^{14}{ }^{25}$; most of the pig spirochaetes have more (eight or nine), ${ }^{11}$ although one isolate with five axial fibrils caused diarrhoea when fed to pigs in pure culture. ${ }^{12}$

We found these organisms in the faeces of 16 of 330
Asian patients (4.8\%), and 12 of these had visited or been resident in the Indian subcontinent within the preceding six months. Only one patient had gastrointestinal symptoms, a 2 year old girl with diarrhoea who had recently returned from Pakistan. No recognised enteric pathogens were detected in the faeces of this patient, and spirochaetes were absent at followup one month later. Early studies using light microscopy suggested that $100 \%$ of the native population in West Africa had been colonised with intestinal spiral organisms compared with $3 \%$ of British soldiers. ${ }^{23}$ In Brussels 21 of 1679 faecal specimens (1.2\%) were positive for spirochaetes on culture $(n=16)$ or in stained films $(n=5)$. Seventeen of the 21 patients had diarrhoea, but eight also had a known enteric pathogen. Of 129 patients with diarrhoea and 93 asymptomatic controls, in Rwanda (Proceedings of First European Congress of Clinical Microbiology, Italy 1983) $18(14.0 \%)$ and $21(22.6 \%)$, respectively, had spirochaetes cultured from faecal specimens. Ethnic groups differ in their dietary habits; diet may influence the composition of the intestinal flora, but the evidence in man is not as clear as that in studies on experimental animals. ${ }^{27}$

Spirochaetes have been cultured from the faeces of 11 Italian patients with various gastrointestinal disorders, ${ }^{25}$ but the incidence in asymptomatic Italians has not yet been reported. The only reported bacteraemia was associated with bloody diarrhoea in a patient with alcoholic cardiomyopathy who initially responded to treatment with penicillin but who later died with cardiac decompensation in hepatorenal failure. $^{26}$ 
A smaller spirochaete with four axial fibrils has been isolated from patients with histologically confirmed intestinal spirochaetosis, in which biopsy specimens showed a mass of organisms coating the mucosa of the bowel. ${ }^{28}$ This organism grows on blood agar with spectinomycin but requires at least 14 days of anaerobic incubation. It has been named Brachyspira aalborgi. We isolated a similar organism from a patient with intestinal spirochaetosis, which died on subculture, ${ }^{29}$ but have not isolated the larger spirochaetes from patients with histologically confirmed spirochaetal colonisation, although motile spirochaetes have been observed by darkground microscopy of material obtained on rectal swabs. Although various gastrointestinal disorders have been attributed to heavy colonisation of the intestinal mucosa with spirochaetes, surveys of large numbers of patients have found spirochaetosis in the normal bowel and no association with any specific gastrointestinal disease. ${ }^{430}$

Examination of nine of 14 rectal biopsy specimens obtained from healthy volunteers in southern India showed numerous spiral organisms coating the mucosa. ${ }^{31}$ Abnormalities in the ultrastructural morphology of the rectal mucosa, compared with those from biopsy specimens from subjects living in temperate zones, were seen in all 14 specimens, but all volunteers had no gastrointestinal symptoms and normal results for tests of intestinal absorption.

Intestinal spirochaetosis is more common among homosexuals $(36 \%)$ than in the general male population of west Scotland (3\%), but again there is no evidence that it is of any pathological importance. ${ }^{15}$ We cultured spirochaetes from $20.6 \%$ of the homosexuals investigated; none had gastrointestinal symptoms.

The biochemical characteristics of our isolates are similar to those described by others ${ }^{25}$ and to spirochaetes isolated from pigs and other animals. ${ }^{11} 16 \mathrm{It}$ has been suggested that indole production, fructose fermentation, production of $\alpha$ glucosidase and $\beta$ glucosidase, and lack of $\alpha$ galactosidase activity are all markers of pathogenicity in pig spirochaetes, ${ }^{11} 19$ but other workers have disproved this. ${ }^{121632} \mathrm{Br}$ aalborgi has a different profile of enzyme production compared with that of other intestinal spirochaetes. ${ }^{28}$

The cellular fatty acids of strains of $\mathrm{Tr}$ hyodysenteriae and $\mathrm{Tr}$ innocens have been described $^{2133}$ as being predominantly palmitic acid (16:0) and also a 15-carbon chain isomer and tetradecanoic acid. In the human and porcine spirochaetes examined the principal components we detected were palmitic acid methyl ester (16:0) with a smaller peak of 13 methyl tetradecanoate ester. The first two peaks, present in all isolates, were thought to represent a $\mathrm{Cl3}$ fatty acid and $3 \mathrm{OH}$ tetradecanoate. Traces of 17 - and 18-carbon fatty acids and pentadecanoate were also detected. The human isolates are therefore similar in fatty acid composition to the porcine isolates, and like Tr hyodysenteriae, differ considerably from other treponemes. ${ }^{34}$

The biochemical similarities between human and porcine spirochaetes are not unexpected, as DNA hybridisation studies have shown a close genetic correlation between the two groups of organisms. ${ }^{35}$ All strains were sensitive to metronidazole, and this may be the preferred antibiotic if serious infection is suspected with these organisms. Penicillin may be ineffective as some strains seem to be resistant and may produce a novel $\beta$ lactamase. This property is currently being investigated.

In conclusion, our work and that of others indicates that spirochaetes very similar to those found in pigs and other animals are found in the gastrointestinal tract of man. Spirochaetes may cause severe diarrhoea in pigs, but there is no conclusive evidence that these organisms cause disease in man. They are more common in Africans and Asians than in Europeans and are commonly found in homosexuals. The reasons for this are not known.

We thank all our colleagues in West Yorkshire who assisted us in the collection of specimens, particularly Dr WM Edgar, Mr RC Macdonald, and Dr MA Waugh. D Hunter MAFF Animal Health Centre, Leeds, kindly donated the porcine spirochaetes.

\section{References}

${ }^{1}$ Escherich T. Klinisch-therapeutische Beobachtungen aus der Cholera. Epidemie in Neapel. Arztliche Intelligenzblatt 1884;31: $561-4$.

${ }^{2}$ Macfie JWS. The prevalence of Spirochaeta eugyrata in Europeans and natives in the Gold Coast. Lancet 1917;i:336-40.

${ }^{3}$ Fantham HB. Remarks on the nature and distribution of the parasites observed in the stools of 1305 dysenteric patients. Lance 1916;i:1165-6.

${ }^{4}$ Lee FD, Kraszewski A, Gordon J, Howie JGR, McSeveney D, Harland WA. Intestinal spirochaetosis. Gut 1971;12:126-33.

${ }^{5}$ Harland WA, Lee FD. Intestinal spirochaetosis. $\mathrm{Br} \mathrm{Med} J$ 1967;iii:718-9.

${ }^{6}$ Harris DL, Kinyon JM. Significance of anaerobic spirochaetes in the intestines of animals. Am J Clin Nutr 1974;27:1297-304.

${ }^{7}$ Takeuchi A, Jervis HR, Nakazawa H, Robinson DM. Spiral shaped organisms on the surface colonic epithelium of the monkey and man. Am J Clin Nutr 1974;27:1287-96.

${ }^{8}$ Gad A, Willen R, Furugard K, Fors B, Hradsky M. Intestinal spirochaetosis as a cause of longstanding diarrhoea. Upsala $J$ Med Sci 1977;82:49-54.

${ }^{9}$ Shera G. Specific granular lesions associated with intestinal spirochaetosis. Br J Surg 1962;50:68-77.

${ }^{10}$ Douglas JG, Crucioli V. Spirochaetosis: a remediable cause of diarrhoea and rectal bleeding. Br Med J 1981;283:1362.

${ }^{11} \mathrm{~K}$ inyon JM, Harris DL. Treponema innocens a new species of intestinal bacteria and emended description of the type strain of Treponema hyodysenteriae. Int J Syst Bacteriol 1979;29:102-9.

12 Taylor DJ, Simmons JR, Laird HM. Production of diarrhoea and dysentery in pigs by feeding pure cultures of a spirochaete 
differing from Treponema hyodysenteriae. Vet Rec 1980;106:326-32.

${ }^{13}$ Songer JG, Kinyon JM, Harris DL. Selective medium for isolation of Treponema hyodysenteriae. J Clin Microbiol 1976;4:57-60.

${ }^{14}$ Tompkins DS, Waugh MA, Cooke EM. Isolation of intestinal spirochaetes from homosexuals. J Clin Pathol 1981;34:1385-87.

${ }^{15}$ McMillan A, Lee FD. Sigmoidoscopic and microscopic appearance of the rectal mucosa in homosexual men. Gut 1981;22:1035-41.

${ }^{16}$ Lemcke RM, Burrows MR. A comparative study of spirochaetes from the porcine alimentary tract. $J$ Hyg 1981;86:173-82.

${ }^{17}$ Phillips KD. A simple and sensitive technique for determining the fermentation reactions of non-sporing anaerobes. J Appl Bacteriol 1976;41:325-8.

${ }^{18}$ Sanna A, Dettori G, Grillo R, Rossi A, Chiarenza D. Isolation and propagation of a strain of Treponema from the human digestive tract-preliminary report. L'Igiene Moderna 1982;77:287-97.

${ }^{19}$ Hunter D, Wood T. An evaluation of the APIZYM system as a means of classifying spirochaetes associated with swine dysentery. Vet Rec 1979;104:383-4.

${ }^{20}$ Moss CW. Gas liquid chromatography as an analytical tool in microbiology. J Chromatogr 1981;203:337-47.

${ }^{21}$ Matthews HM, Kinyon JM. Cellular lipid comparisons between strains of Treponema hyodysenteriae and Treponema innocens. Int J Syst Bacteriol 1984;34:160-5.

${ }^{22}$ O'Callaghan CH, Morris A, Kirby SM, Shingler AH. Novel method for detection of $\boldsymbol{\beta}$-lactamases by using a chromogenic cephalosporin substrate. Antimicrob Agents Chemother 1972;1:283-8.

${ }^{23}$ Chia SP, Taylor DJ. Factors affecting the survival of Treponema hyodysenteriae in dysenteric pig faeces. Vet Rec 1978;103:68-70.

${ }^{24}$ Taylor DJ, Lysons RJ, Bew J, Stevenson R, Lemcke MR. Survival of Treponema hyodysenteriae in samples of dysenteric pig faeces sent by post and stored at room temperature. Vet Rec 1985;116:48-9.

${ }^{25}$ Sanna A, Dettori G, Agliano AM, et al. Studies of treponemes isolated from human gastrointestinal tract. L'Igiene Moderna 1984;81:959-73.

${ }^{26}$ Lambert T, Goursot G. Diarrhee aigue avec hemocultures et coprocultures positives a Treponema. Médecine et Maladies Infectieuses 1982;12:276-8.

${ }^{27}$ Hentges DJ. Does diet influence human faecal microflora composition? Nutr Rev 1980;38:329-36.

${ }^{28}$ Hovind-Hougen K, Birch-Andersen A, Henrik-Nielsen R, et al. Intestinal spirochaetosis: morphological characterization and cultivation of the spirochete Brachyspira aalborgi gen. nov. sp. nov. J Clin Microbiol 1982;16:1127-36.

${ }^{29}$ Tompkins DS, Cooke EM, MacDonald RC, Abbott CR. Spirochaetosis: a remediable cause of diarrhoea and rectal bleeding? $\mathrm{Br}$ Med J 1982;284:52.

${ }^{30}$ Nielsen RH, Orholm M, Pedersen JO, Hovind-Hougen $\mathrm{K}$, Teglbjaerg PS, Thaysen EH. Colorectal spirochaetosis: clinical significance of the infestation. Gastroenterology 1983;85:62-7.

${ }^{31}$ Mathan MM, Mathan VI. Rectal mucosal morphological abnormalities in normal subjects in southern India: a tropical colonopathy? Gut 1985;26:710-7.

${ }^{32}$ Picard B, Lariviere S, Saheb SA. Etude comparative des caractères biochimiques de treponemes hemolytiques isoles du porc. Can J Microbiol 1980;26:985-91.

${ }^{33}$ Matthews HM, Yang T-K, Jenkin HM. Alk-l-enyl ether phospholipids (plasmalogens) and glycolipids of Treponema hyodysenteriae. Analysis of acyl and alk-l-enyl moieties. Biochim Biophys Acta 1980;618:273-81.

${ }^{34}$ Cohen PG, Moss CW, Farshtchi D. Cellular fatty acids of treponemes. Br J Vener Dis 1970;46:10-12.

${ }^{35}$ Agliano AM, Dettori G, Branca G, Grillo R, Manzari V, Sanna A. Genetic relationship between human and swine treponema. L'Igiene Moderna 1983;80:699-705.

Requests for reprints to: Dr DS Tompkins, Department of Microbiology, University of Leeds, Leeds LS2 9JT. England. 